\title{
Research on One-Stop and Full-Support Mode of Intellectual Property Transaction
}

\author{
Qin Luo, Wei Song \\ School of Public Affairs, University of Science and Technology of China, Hefei, China \\ Email: lq1030@mail.ustc.edu.cn
}

How to cite this paper: Luo, Q. and Song, W. (2017) Research on One-Stop and FullSupport Mode of Intellectual Property Transaction. Open Journal of Social Sciences, 5, 163-174.

https://doi.org/10.4236/jss.2017.56015

Received: April 29, 2017

Accepted: June 17, 2017

Published: June 20, 2017

Copyright $\odot 2017$ by authors and Scientific Research Publishing Inc. This work is licensed under the Creative Commons Attribution International License (CC BY 4.0).

http://creativecommons.org/licenses/by/4.0/

\section{(c) (i) Open Access}

\begin{abstract}
Intellectual property right transaction is the key link of the successful transformation of scientific and technological achievements, and it plays an important role in the process of promoting the integration of S\&T and economy. In order to break the gap between S\&T and the economy, the state vigorously advocating the construction of comprehensive service platform for intellectual property rights is based on the whole process of transformation of scientific and technological achievements, but the current real sense of the whole support platform is numbered. Under the guidance of the innovation value chain theory, this paper expounds the connotation and essential characteristics of the one-stop and full-support platform of intellectual property transaction, and summarizes the five-stage model of intellectual property transactions and the basic service requirements during the whole process of intellectual property transactions, then builds the service system of the one-stop and fullsupport mode based on the overall process of intellectual property transaction and analyzes the unique advantages of the mode. Finally, the paper constructs the internal and external support system so as to improve the construction and development of one-stop and full-support platform mode.
\end{abstract}

\section{Keywords}

Intellectual Property Transaction, One-Stop, Full-Support, Platform Mode

\section{Introduction}

Intellectual property trading platform plays a major role in the process of promoting the integration of economy and technology [1]. China has a large number of various types of intellectual property trading platform, but the function of these platforms is limited to the release of information and lack of active service awareness. Platforms are self-contained. There is still a big gap in providing full service [2]. The development of the Internet and the improvement of modern 
information technology provide new conditions for the development of intellectual property right transactions. The deep integration between the "Internet+" and all areas has boosted the transformation and upgrading of intellectual property right trading platform [3]. The one-stop service concept is based on the whole process of scientific and technological achievements. Transformation was also applied to the field of science and technology service intermediary, which promoted the rise of one-stop intellectual property transaction service platform, and many places in our country were exploring the construction of one-stop service support platform. At present, there are a lot of various types of intellectual property trading platform in our country, but most of these platforms are smaller, and the service areas and levels are very limited. The principal functions of the platform are limited to primary technical project information releases and simple technical product display. The majority of platform operators still take the traditional passive supply-oriented service model and lack of initiative service consciousness. Most of the services provided by the platform often stay in the upstream link of the industrialization chain of scientific and technological achievements. Besides, the majority of intellectual property trading platform in China is established under the guidance of the government. As a result of the lack of uniform platform norms and technical standards, the fragmentation is serious.

In addition, the operation mechanism and model of one-stop and full-support platform lack strong theoretical support, theoretical research lags behind the practice development. The concept of one-stop or full-support intellectual property trading platform has appeared in some scholars' studies. Some researchers have analyzed the fourth party platform mode that can meet all the needs of customers and put forward the concept of one-stop service platform [4]. But the focus of their research is to propose a new concept of the fourth party platform, and is committed to the definition of the concept of the fourth party. Li Lina has explored the one-stop model in the field of science and technology services, but its research has only summarized the service function of the "one-stop" technology service platform [5]. Chen Xuexiao proposed the one-stop service system of intellectual property, his research just focus on the system design and function realization [6]. Geng Yibing from the perspective of the whole process of technology trading activities to construct a comprehensive service platform for open innovation, but its research focuses on the financing model of intellectual property rights trading platform [7]. Some scholars have put forward the "one-stop full process value-added" model, but they focus on the analysis of the function and business process of technology trading platform [8]. In addition, there are scholars put forward the technology demand-oriented technology trading model, technology transactions life cycle service model based on the research of some typical platform. Although one-stop intellectual property trading platform has been involved in those theoretical studies, but the study is fragmented and general, the specific analysis is not deep enough, and didn't form a complete theoretical system. Therefore, this paper uses the theory of transaction cost, informa- 
tion economics theory and innovation value chain theory to analyze the connotation, advantages and service system of one-stop and full-support mode of intellectual property transaction systematically, so as to guide the further development of China's intellectual property trading platform.

\section{Connotation Characteristics of One-Stop and Full-Support Mode of Intellectual Property Transaction}

One-stop service was originally developed from the business field, it takes the customer as the center and fully consider the customer needs, so that customers can enjoy one-stop service. Later, this concept has been gradually introduced into the field of government administrative services, and has been applied to the field of science and technology services. The one-stop and full support mode is based on the various service demands required in the process of intellectual property transactions. The mode is proposed to ensure the success rate of the intellectual property right transaction and realize the value of intellectual property. The basic connotation of the one-stop and full-support mode refers to the integration of the information, services and resources needed in all aspects of intellectual property transactions from the whole process, so that the subject of intellectual property transactions can obtain a complete one-stop service. This mode does not emphasize that the IP trading platform needs to have all the service capabilities covering all service levels, but rather to establish a network link with professional intermediaries and stakeholders, and to provide service channels for the transaction subject.

\subsection{Information Integration}

One-stop and full-support platform is a highly integrated platform of information. Intellectual property information service is the basic and most important function of the platform. The platform is required to collect, process, organize, analyze and publish information from three aspects. First is the information provided by the platform's main service objects, including the basic information and main demands of the buyer, the scientific and technological achievements supply information provided by the sellers. The platform needs to integrate the information of supply and demand in the market effectively, so as to realize the abutment between supply and demand, and provide relevant value-added services. The second is to integrate the different intermediary service information needed during the whole process of intellectual property transaction. On the one hand, it is the integration of all the same kind of intermediary information about the transaction. On the other hand, it is the integration of different types of intermediary information during different links. Third, integrate the policy information introduced by the central and local government, industry information and standard information.

\subsection{Service Integration}

The one-stop and full-support platform is a highly integrated platform for ser- 
vice. It integrates all the services required for the transformation of scientific and technological achievements from both horizontal and vertical levels. From the horizontal, there are many service providers on the market for certain intermediary services in one part of intellectual property transaction. As the development orientation and service level of these similar intermediaries are not the same, so the quality of service, the service model and the service price are different. It is necessary to integrate the same kind of intermediary services at different levels from the horizontal, so as to improve the satisfaction of users. The vertical integration of services refers to the dynamic integration of the service intermediary resources in all aspects of the intellectual property transaction on the basis of the horizontal integration of services, and provides a complete solution for the client.

\subsection{Subject Pluralism}

The smooth implementation of the transformation of intellectual property cannot do without money, markets, services, personnel and other innovative resources, it is necessary to integrate the government, enterprises, universities, research institutes, financial institutions and intermediaries. The traditional intellectual property trading platform only gathered the two sides of the transaction, in the course of the completion of intellectual property transactions, buyers and sellers often need to search for other related parties discretely. The one-stop and full-support platform of intellectual property transactions is a comprehensive participatory platform. It gathered the Government-Business-University-Research-Financial-Intermediary together by using the network tools and its own resources, and provide smooth channels for buyers and sellers access to various services and innovative resources. Government and relevant departments are vital participants in technology trading, the enterprises, universities and research institutes are the main service groups, the financial institutions and intermediary can be seen as the third-party service agencies, they have a pivotal role in the innovation chain.

\subsection{Combination of Online and Offline}

The one-stop and full-support platform is the combination of the online system and offline system. Due to the constraints of geographical factors and the influence of information barriers, information searching cost and negotiation cost of the traditional offline trading platform is often high. The One-stop and fullsupport service platform combined with the online platform and offline market where the subject can realize the online product listing or demand releasing. This mode can break the information barriers, so as to achieve the sharing of information resources, and shorten the search time and search costs. Through the online negotiation and online bidding system, we can eliminate obstacles of regional segmentation, and both parties can achieve real-time communication and transaction. But the patent, copyright and other intellectual property belonging to the intangible assets, the online platform alone cannot assess the value 
of technology accurately, so it is necessary to give full play to the role of the entity market to regulate the trading behavior.

\section{Construction of One-Stop and Full-Support Mode of Intellectual Property Transaction}

\subsection{Analysis of Intellectual Property Transaction Process}

The innovation value chain theory regards the creation of the creativity to the final commercialization as a complete chain. Each stage requires a certain amount of resources, and the output of each node is also known as the investment of the next stage, the value of the innovation value chain can only be realized by the successful completion of the industrialization of scientific and technological achievements [9]. Intellectual property transactions are a complicated and dynamic economic activity. Based on the current situation of intellectual property transaction, this paper proposes the five-stage process model of intellectual property transaction from the perspective of innovation value chain.

Stage 1: The information searching stage. At this stage, the supplier of technology in the market search for the buyer and disclose their own specialized information to the market or the corresponding intermediaries (platform) by using their own networks or information resources. And the demand side of the technology is also looking for a technology that complies with the requirements through platforms or other means.

Stage 2: The matching stage of information, the effective matching of supply and demand information is a precondition for the realization of intellectual property transactions. In this stage, the platform needs to evaluate and filter intellectual property, identify those projects with market prospect. At the same time, the platform finds qualified buyers (sellers) in the market according to the information provided by the supply and requisitioning parties and matching the supply and demand information.

Stage 3: Consultation and negotiation stage. After the information matching, the transaction subject with transaction intention can negotiate on the trading platform. Before the formal cooperation, the transaction subject can negotiate on the content and innovation point of the intellectual property rights, as well as the transaction mode and the specific terms of the contract or the compliance mechanism before the formal agreement is reached.

Stage 4: The transfer phase. This stage is mainly to sign the transaction contract and complete the delivery of intellectual property rights, form a formal partnership. The contents of the delivery include the transfer of the usage rights (license) or ownership (technology sales) and so on.

Stage 5: The application phase that is, the absorption, application and implementation stage of scientific and technological achievements, is the last link of the innovation value chain. The ultimate goal of the intellectual property rights transaction is to realize the industrialization of scientific and technological achievements. 


\subsection{Analysis on the Demand of Intellectual Property Transaction Service Based on the Whole Process}

According to the analysis of the process of intellectual property transactions, the transaction rate will not be ideal if the subject only focused on the transfer phase, the seller and the buyer will have a corresponding demand in each stage. Therefore, it is necessary to extend the intellectual property transaction service value chain and provide full-support during the whole process according to the characteristic of the intellectual property transaction process. Based on the five-stage model build above, we discuss the service requirements of both buyers and sellers throughout the transaction.

In the information search stage, the enterprises will be faced with the technical problems or the need to improve the production and the profitability and innovation ability of the enterprise by introducing the technological achievements. Therefore, they need to quickly search for the technologies that meet the requirements in the market, and release the requirements information or technical problem information. Universities and research institutes is the main producer of scientific and technological achievements in our country, they need the help from appropriate platform to achieve the rapid transformation of scientific and technological achievements, they also need the help from the intermediary platform to improve the packaging and Publicity of their intellectual property. At the same time, the subject of S\&T research can use the platform to know the existing technology development situation, so as to reduce the duplication of existing technologies, enhance the quality of technology and reduce the risk of infringement.

In the information matching stage, the two parties of an intellectual property transaction have to carry on the selection and matching of each other and further searching and querying detailed information. In the case of patent transactions, the demand side of intellectual property rights wants to know the overall situation of patent technology and its technical characteristics, the patent ownership and technical details etc. The owner of the patent often wants to inquire and understand the specific qualifications and the actual situation of the transferee. At the same time, the two parties of an intellectual property transaction also need to select the best partner with the help from the platform.

At the consultation and negotiation stage, both sides of the supply and demand have to communicate and negotiate with each other in order to decrease the risk of trade and the influence of asymmetric information. They need intellectual property intermediaries to set up communication platforms and create more effective negotiating patterns for them. Due to the restriction of professionalism and the ability limit, the both parties need platform to identify the legitimacy of the intellectual property rights, to evaluate the value of technology, to analyze the feasibility of the technology project for the importing party, to analyze the application prospect for the supplier. In addition, in the conduct of intellectual property transfer negotiations, the two sides also need the platform provides query service and consulting services from a professional point and 
answers some of the doubts about the intellectual property rights transaction.

During the transfer phase, the main task is to sign the contract according to relevant laws, regulations and policies. The intermediary platform can help draw up the draft and provide litigation, mediation, arbitration, judicial authentication and additional legal services, as well as the financial service.

After the signing of the contract, the buyer and the seller need to change the registration of property rights according to the state law. In order to ensure the fulfillment of their obligations and the realization of the rights, the intellectual property rights trading platform needs to provide specialized contract registration and contract supervision services. In addition, in order to assure the successful implementation of the technology, it may also need to provide follow-up service, such as business planning, personnel training, seed investment and other financial services.

\subsection{The Service System Construction of One-Stop and Full-Support Mode}

Based on the five-stage model of intellectual property transaction and its service demand during the process, we propose the one-stop and full-support service platform mode of intellectual property transaction from the perspective of innovation value chain. The model is mainly composed of five service systems.

First, information service subsystem. The basic function of this system is to meet the demands of searching information, releasing information and information matching. The one-stop and full-support platform collects a wide range of effective information in the market through a variety of channels, and establishes technical resources database through the information integration, classification and processing. On the one hand, it releases the technical problems or the technology introductory information to the market, as well as the exhibition information and the regulatory policy information. On the other hand, it provides comprehensive information services for the users through the integration and classification of information.

Second, consulting services subsystem. Consulting service subsystem provides various types of consulting services for users. Establish expert pool or talent pool through the cooperation with experts and scholars who have deep attainments and professional standards in the field of technology transaction. At the same time, provide service channels for users with consulting needs through the corporation with professional consulting services, such as venture capital institutions, patent offices, law firms, contract registration agencies, etc. The services provided include technical advice before the transaction, feasibility study of technical projects, legal advice, also include transaction mode consulting and contract registration consulting services.

Third, transaction service subsystem. Transaction service subsystem is the most important service system of the one-stop and full-support mode. It provides online and offline trading channels for the buyers and sellers during the process of technology transfer. The online platform has the functions of online 
results listing, online negotiation, online auction, online bidding. In view of the particularity of intellectual property rights, the platform also provides the corresponding offline consultation channels. And provide contract signing service, payment settlement service.

Fourth, value-added service subsystem. This system provides exclusive customization service based on the basic service of the transaction subject. At present, the main value-added services provided by the one-stop and full-support platform are customized service, information push and service recommendation. Users of the platform can customize their services according to their own needs, such as subscribing to relevant industry information. The platform will dig out the special needs of customers according to their search traces and transaction records, then push the information they may be interested in, and achieve accurate service. Service recommendation is a kind of active service, the platform will follow up the transaction process and response to the service demand produced in the process rapidly, such as financing and personnel training. The value added service has jumped out of the single link of technology transfer stage, concerned about the starting point and the end point of the chain of scientific and technological achievements transformation.

\section{Advantages of One-Stop and Full-Support Mode}

\subsection{Reduce Transaction Costs and Risks}

Neither the buyer nor the seller, nor the relevant intermediaries, can fully grasp all the information of the entire market. One-stop and full-support platform gathering the scientific and technological achievements information, expert information and all kinds of innovative elements effectively, the users of the platform can query information through the network search engine, it accelerates the flow rate of effective information and effectively reduces the cost of searching for technical information. In addition, online negotiation and online trading system provided by the platform facilitated the technical transactions, greatly saving the cost of offline consultation and improving the efficiency of technical transactions.

\subsection{To Break the Independent Situation of Each Subject}

Intellectual property transactions involving multiparty, such as the supply and demand of scientific and technological achievements, the intermediary service agencies, government departments. In the traditional mode, those subjects are independent and decentralized, they did not form a good cooperative relationship and cannot produce agglomeration effect, the industry chain of the intellectual property rights trading market is in a discrete state [10]. The one-stop full-support platform brings those scattered subjects together by using the information network and forms a technology service alliance. It broke the boundaries of various institutions in the intellectual property trading market, reorganized the industry chain of the intellectual property market, and formed a har- 
monious and innovative service ecology.

\subsection{Provide One-Stop Service Experience}

The service content of one-stop and full-support platform throughout all aspects of the transaction. It begins with the application of intellectual property rights, covering the display of scientific and technological achievements, the assessment of the technology value, the feasibility analysis of the market, the signing of the contract, the legal advice and the financial Support. The diversified needs of the main transaction subjects can be fully met on a single platform with the help of the one-stop and full-support platform. It integrated a variety of service means with the support of modern network technology, and provides a one-stop service experience for the users.

\section{Support System of One-Stop and Full-Support Mode}

The construction and effective operation of the one-stop and full-support platform for intellectual property transactions can't be done without the common support of the internal and external environment. In this section, we construct the internal and external support system, so as to promote the development of one-stop and full-support platform.

\subsection{External Support System}

\subsubsection{Mature Technology Trading Market}

The development of both market and platform is complementary, healthy and mature market is the basis for the survival of the platform. The prosperity of the market will play an important role in promoting the development of the platform. With the continuous development of science and technology innovation, a large number of scientific and technological achievements have emerged in the technology trading market, which leads to the explosive demand for intellectual property trading platform. The improvement of the market directly affects the role of the platform, the more standardized the market. Only when the market rules are transparent, the competition of various platforms in the market can be beneficial. In turn, the efficient operation and expansion of the platform are bound to stimulate the continued prosperity of technology transactions, and promote the continuous progress of technological innovation.

\subsubsection{A Sound Regulatory Environment}

As a new thing, the development of China's intellectual property rights trading market is immature and lack of competition mechanism, the policy support from the government is the key driver of platform construction. From the experience of foreign countries, developed countries have make detailed laws or regulations from the R\&D to the technical application, also made a clear and specific legal interpretation of the technology transfer link, for example, the Japanese government has been using preferential tax policies to encourage the development of technology intermediaries. China should establish and improve the integrity of the legal system. Strengthen policy support. 


\subsubsection{Basic Network Construction}

The level of information integration of the one-stop and full-support platform depends on its own resources to a large extent, it also depends largely on the degree of openness of scientific and technological information resources in the market. The perfect science and technology information resource network are an important foundation for the integration of market resource information in the intellectual property trading platform. It involves all the innovation subjects in the market and should be driven by the government. It cannot be effectively constructed by some platforms. The government should associate with other subjects in the scientific and technological innovation system to improve the construction of scientific and technological information network, improve the integration and development of basic information resources, and promote the development of various kinds of databases.

\subsection{Internal Support System}

\subsubsection{Advanced Technological Means}

In order to realize the full integration of information, services and resources, the one-stop and full-support platform need to establish a multi-function computeraided integrated service system using the push technology, intelligent agent technology, data warehouse and data mining technology, semantic technology. The platform with huge volume of information resources will face some security problems in the virtual network environment, such as information leakage or information damage and so on. Users also question the reliability of online transactions. Therefore, platform operators need to standardize the format and specific parameters of the information through data encryption and other network security technology, in order to avoid the destruction and loss of data information. They need to pay attention to the development of the platform protection system, strengthen the identification and supervision of the platform users and intercept illegal access, so as to guarantee the security of intellectual property rights transactions.

\subsubsection{Active Service Consciousness}

Operating subject of the intellectual property trading platform must have a clear positioning of the platform and set up an active service consciousness. First, they should change the traditional service perspective and find the key point of service, then provide all-round services in the transaction process and reform service details. In addition, providing high quality service should be the development goal of the platform, the platform should improve service quality and establish a good service reputation in the entire industry.

\subsubsection{Professional Talented Team}

Intellectual property rights transaction is a highly integrated professional work with high technical content, Involved with a series of professional fields, such as technology, management, law and economy. The intellectual property transaction practitioners should have a relatively high overall quality. They need to learn 
specialized knowledge, laws and regulations, economic management knowledge and market knowledge, and have some identification, organization, coordination, negotiation, presentation skills. In addition, they should have integrity, fairness and cooperation spirit. To some extent, the level of intellectual property service staff basically represents the overall quality of the intellectual property trading platform. Therefore, develop a proficient talented team is an important condition for the development of intellectual property trading platform.

\section{Conclusion}

The serious disjunction between technology chain and industrial chain is the key reason that restricts the transformation of scientific and technological achievements of our country. It is a powerful way to promote the realization of intellectual property value by setting up an effective intellectual property trading platform. In this paper, we summarize the key problems of the construction of intellectual property trading platform in China and put forward the construction of one-stop and full-support platform mode based on the transaction cost theory, information economics theory and innovation value chain theory. The one-stop and full-support mode of intellectual property rights transaction platform is an innovation of the service process and service model, which is the combination of online model and offline system. We summarize four basic connotation characteristics of one-stop and full-support service platform mode, namely, information integration, resource integration, subject pluralism and a combination of online and offline. And we constructed a five-stage model of intellectual property transactions from information search, information matching, negotiation, transfer transaction to application implementation. Based on the service requirements that may arise from each stage, the article constructs a four module service system from the perspective of innovation value chain, including information module, consultation module, transaction module and value-add module. The one-stop and full-support platform mode has the special advantage that traditional platform does not have, but its construction and effective operation can't be done without the support of internal and external environment. So, it is of great importance to construct a sound internal and external support system. For the external support system, the state should promote the construction of a mature technology trading market and basic network, and should improve and perfect the legal system. For the internal support system, the platform operator should make full use of advanced technology means, enhance the initiative service consciousness and build up a professional team.

\section{References}

[1] Chen, Y. (2005) Reflections on the Construction of Comprehensive Trade Platform of Intellectual Property in China. China Soft Science, No. 3, 154-156.

[2] Gao, G.Q. (2012) Research on the Construction of Intellectual Property Service Platform in China. Legality Vision, No. 4, 294-295.

[3] Lv, G.C. and Jiang, F. (2014) Comparison and Enlightenment of Foreign Online Technology Market Business Model. Commercial Times, No. 1, 92-94. 
[4] Zhao, B. (2011) A Study on the Mode of the Fourth Party Platform of a Technical Trading Organization in Beijing. Chinese Folk House, No. 11, 43-44.

[5] Li, L.N. (2012) Reflections on the Construction of "One-Stop" Mode of Science and Technology Service. Technology Entrepreneurship Monthly, No. 3, 3-4.

[6] Chen, X.X. and Duan, H.Q. (2013) One-Stop Service Platform for Intellectual Property Rights. High Technology and Industrialization, No. 5, 30-34.

[7] Geng, Y.B. (2015) Design of Financing Model for Intellectual Property Rights Trading Platform. Southeast University, Nanjing.

[8] Wu, Y.Y. (2014) Research on Typical Service Mode and Platform of Technology Trading. Southeast University, Nanjing.

[9] Cai, X. (2002) Innovation, Innovative Ethnic Group, Innovation Value Chain and Its Enlightenment. R\&D Management, No. 14, 35-39.

[10] Zhan, Y.J. and Zhang, X.F. (2013) Research on the platform of intellectual property exchange between the two sides of the Taiwan Strait. Strait Law, No. 4, 18-24.

Submit or recommend next manuscript to SCIRP and we will provide best service for you:

Accepting pre-submission inquiries through Email, Facebook, LinkedIn, Twitter, etc. A wide selection of journals (inclusive of 9 subjects, more than 200 journals)

Providing 24-hour high-quality service

User-friendly online submission system

Fair and swift peer-review system

Efficient typesetting and proofreading procedure

Display of the result of downloads and visits, as well as the number of cited articles

Maximum dissemination of your research work

Submit your manuscript at: http://papersubmission.scirp.org/

Or contact jss@scirp.org 